\title{
Miguel Gutiérrez y su celebración de la novela (Piura, Perú, 1940 - Lima, Perú, 2016)
}

\author{
Agustín Prado Alvarado \\ Universidad Nacional Mayor de San Marcos \\ Contacto: apradoa@unmsm.edu.pe

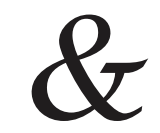 \\ Yo no habría descubierto mi vocación de novelista \\ si no hubiera leído a Dostoievski y Alegría \\ Miguel Gutiérrez
}

\section{Una vocación por la novela}

Miguel Gutiérrez (Piura, 1940 - Lima, 2016) fue uno de los escritores peruanos que en los últimos 25 años desarrolló uno de los proyectos novelísticos más ambiciosos en los márgenes de un estilo realista (y las variantes del realismo que exploró) y una perspectiva cosmopolita de los cuales ha dejado tres novelas importantes: La violencia del tiempo (1991), Babel, el Paraíso (1993) y El mundo sin Xóchitl (2001). Además de la escritura novelística Gutiérrez escribió diversos ensayos, algunos de ellos totalmente polémicos y rebatibles como su libro $\mathrm{La}$ generación del 50: un mundo dividido (1988) donde vociferó sin reparos su filiación ideológica con Sendero Luminoso y su cabecilla Abimael Guzmán a quien consideraba, increíblemente, una de las mentes más brillantes de la Generación del 50.

Estas radicales posiciones políticas no impidieron a Miguel Gutiérrez apreciar literariamente a escritores como Mario Vargas Llosa y Julio Ramón Ribeyro a quienes en su ensayo acusó con las mismas consignas que impregnan los catecismos de la izquierda. Y aunque en otros libros este radicalismo se atenuó encontraremos en sus escritos reflexivos a un Gutiérrez que leyó, examinó y celebró a la novela como género literario desde sus orígenes en la Grecia del siglo I d.C., hasta los narradores más jóvenes del siglo XXI. 
Agustín Prado Alvarado

Esta firme vocación novelística se inició en sus años de adolescente en su calurosa tierra natal, Piura, como lo ha confesado en el más entrañable y autobiográfico de sus libros ensayísticos Celebración de la novela (1996). Para Gutiérrez fueron dos autores quienes lo capturaron definitivamente para las filas de la literatura: el escritor ruso Fiódor Dostoievski y el novelista peruano Ciro Alegría. La lectura de Crimen y castigo y de Los perros hambrientos inició el sendero literario que marcaría su opción por el estilo realista, las complejidades en la psiquis de los personajes y el aprecio por las historias del mundo rural.

La existencia de Crimen y castigo y su perturbador argumento fue conocida por Miguel Gutiérrez a los siete años por una tía materna quien le confesó sobre la existencia de Dostoievski y su admiración por la historia protagonizada por Raskólnikov, un asesino, y Sonia, una prostituta; sin embargo, Gutiérrez recuerda que es recién a los 14 años cuando esta novela llegó a sus manos adolescentes al pedir el libro en la biblioteca municipal de Piura. Esos días de lectura impactaron en su gusto literario y en su visión del mundo: "Por eso la influencia que Dostoievski ejerció en mí no tuvo carácter literario sino vital, pues alcanzaba a mi propio sentimiento y visión de la vida" (Gutiérrez 1996: 89). La novela de Dostoievski permitió que Gutiérrez empezara a atisbar su entorno piurano desde una nueva perspectiva en la cual encontraría personajes marginales y de pobres gentes (al decir de Dostoievski) con historias marcadas por cicatrices familiares e individuales conocidas mediante las historias orales que escuchaba a vecinos, amigos y parientes, estos personajes de estirpe dostoievskiana de la calurosa Piura se incorporarían en el futuro a sus novelas.

Los perros hambrientos, uno de los relatos clásicos del escritor Ciro Alegría, fue la otra novela decisiva en los años escolares de Piura. Gutiérrez encontró en la narración de Alegría y posteriormente en sus otras novelas La serpiente de oroy El mundo es ancho y ajeno todo un mundo rural con personajes campesinos e imponentes paisajes capaces de cumplir roles protagónicos en soberbias narraciones: "Para mi asombro y feliz enseñanza, Los perros hambrientos revelaba una realidad rural en la que los protagonistas eran indios y cholos, 
sometidos, en calidad de colonos, al poder de los grandes terratenientes blancos, (...) descubrí que el maravilloso ámbito de la novela, del espacio podía estar dignificado por personajes del mundo popular, pero no en calidad de comparsas, ni como seres pintorescos" (Gutiérrez 1996: 94-95). En las novelas del escritor piurano se puede apreciar las huellas de la obra Ciro Alegría, especialmente en tres aspectos: 1) la descripción de los pueblos y paisajes rurales; 2) los relatos orales contaminados de la historia peruana y personajes de leyenda como las hazañas de los bandoleros; 3 ) el placer de contar un relato donde la historia envuelva al lector de principio a fin. En una novela como $L a$ violencia del tiempo podemos encontrar este doble legado: el del novelista peruano y del escritor ruso como se aprecia en la descripción de los paisajes, los personajes marginales y las historias orales que se cuelan en el texto.

\section{Miguel Gutiérrez y su escritura novelística}

Otra ladera intelectual de Miguel Gutiérrez es su formación académica. Terminado sus estudios escolares en Piura se trasladó a Lima para ingresar en la Pontificia Universidad Católica del Perú, institución que dejó para trasladarse al programa de Literatura de la Universidad Nacional Mayor de San Marcos. En Lima empezó una nueva etapa de lecturas de novelas, especialmente del siglo XX provenientes de la literatura europea, norteamericana, latinoamericana y peruana. En su evocación de los años universitarios recuerda que fueron las obras de Jean Paul Sartre y Albert Camus por las cuales empezaría su conocimiento de las técnicas narrativas, el manejo de nuevos tipos de narrador, el cuidado del lenguaje, entre otros códigos de la novelística contemporánea: "Pero Sartre no sólo influyó en mí en el pensamiento, y si tú quieres en la vida, sino en el ámbito estrictamente literario. Por ejemplo, los de EI muro, especialmente «Intimidad» e «Infancia de un jefe», me producían extrañeza estética y perturbación moral" (Gutiérrez 1996: 109); otras lecturas que complementaban su propia celebración de la novela fueron los textos correspondientes a las disciplinas de los estudios literarios que finalmente lo condujeron a graduarse con una tesis titulada Estructura e ideología en Todas las sangres. 
Agustín Prado Alvarado

En la ciudad de Lima conoció a Washington Delgado y José María Arguedas (a quienes había mostrado sus primeros cuentos) y frecuentó a varios integrantes de la Generación del 50. La amistad que tuvo con Oswaldo Reynoso los llevó a fundar la controversial revista Narración (1966 - 1974) de abierta filiación marxista. En esta revista editó una crítica a La casa verde de Mario Vargas Llosa donde se aprecia una lectura de carácter contenidista desde la órbita de la literatura comprometida. En este texto encontramos a un lector que ha optado por una visión de la literatura ligada al compromiso social, la ideología marxista y la lucha de clases, pensamiento que lo acompañará en los años siguientes como se puede apreciar en sus declaraciones de 1973: "Como se anunciara desde los años del manifiesto, la historia marcha hacia la edificación de la sociedad sin clases, sin embargo, ahora sabemos que el camino no es fácil, que la revolución puede ser traicionada (...) Una novelística que no tenga en cuenta esta perspectiva histórica y los obstáculos que tiene que superar (en lo interior y exterior) para alcanzar la meta, no añadirá nada realmente nuevo a nuestra narrativa" (Oquendo 1973: 41).

En 1969 se editó en el sello de la editorial Milla Batres su primera novela. El libro situaba su argumento en el mundo escolar de Piura, las vivencias de los adolescentes, las primeras amistades, el despertar sexual, la educación religiosa y el ambiente piurano todo este mundo de provincia relatado bajo un estilo realista, aunque algunos pasajes ya bordea tintes surrealistas que empiezan a distanciarlo del relato mimético. La novela no tuvo mucha fortuna literaria por la discreta recepción por parte de la crítica. Para aquella década de los años sesenta Miguel Gutiérrez había empezado su labor como maestro en colegios de provincia, continuó sus lecturas de novelas - una de los corpus novelísticos que llegó a conocer cabalmente fue la narrativa soviética - y asumió el marxismoleninismo como horizonte de vida (hasta abrazar el radicalismo con el pensamiento maoísta), en los años setenta y ochenta recorrió gran parte del Perú, siguió en su labor de maestro en los claustros universitarios de la Universidad Enrique Guzmán y Valle y emprendió un viaje por tres años a la China 
Miguel Gutiérrez y su celebración de la novela

posterior a Mao Tse Tung.

\section{Celebración de la novela para Miguel Gutiérrez}

En la década de los años ochenta - después de diecinueve años sin editar una nueva novela, salvo un adelanto de ella- se publicó Hombres sin caminos (1988), una narración mucho más madura que su primer libro, con un atractivo tema como el bandolerismo escenificado en Piura y donde se inicia la historia de los Villar, familia importante para su mundo novelístico. La publicación ese mismo año de su radical ensayo La generación del 50: un mundo dividido pusieron a Gutiérrez en la polémica literaria con opiniones favorables hacia su novela y duras pullas hacia su ensayo.

Aunque es con la publicación de La violencia del tiempo que recién empezaría la celebración de la novela para Miguel Gutiérrez, la primera edición estaba editada en tres volúmenes que envolvían centenares de páginas y obtuvo la atención de algún sector de la prensa que anunciaba la novela como uno de los proyectos más imponentes de la literatura peruana. La violencia del tiempo se inscribía en lo que se ha denominado proyecto de novela que aspira a la totalidad por la diversidad de historias que recorren el libro, entre las que destacan las correspondientes a la familia mestiza de los Villar, la formación de Martín Villar y los relatos ocurridos en Europa como los hechos históricos ocurridos en la Comuna de París (1871) y la Semana Trágica de Barcelona (1909). Desde nuestra lectura consideramos a esta ampulosa novela como una narración con muchos puntos a favor, aunque no necesariamente como un libro contundente puesto que apreciamos varios pasajes poco logrados como los acontecidos en Piura aunque también reconocemos historias más atractivas como la protagonizada por Martín Villar a los que habría que resaltar los logrados episodios de la Historia europea.

El mérito de Gutiérrez no solamente se encuentra en haber escrito una de las novelas más codiciosas de la literatura peruana (que consiguió posicionarlo en un lugar más visible en el sistema de recepción literaria en el Perú

e incluso fue favorecido por el reconocimiento de un sector de la crítica y una 
Agustín Prado Alvarado

nueva comunidad de lectores), sino que este libro le sirvió como un práctico laboratorio novelístico que permitió explorar diversas temáticas y recursos estilísticos que permitirían narraciones más logradas en estructuras más compactas como Babel, el Paraíso o El mundo sin Xóchtil e incluso su última novela Kymper (2014), además de continuar escribiendo sobre sus escritores predilectos a quienes siguió celebrando sus novelas en diversos, polémicos y amenos ensayos.

\section{Referencias bibliográficas}

Gutiérrez, Miguel (1966) Mito y aventura en La casa verde. Narración, (1), noviembre 1966, pp. 31-32.

Gutiérrez, Miguel (1969). El viejo saurio se retira. Lima, Editorial Milla Batres.

Gutiérrez, Miguel (1973). Respuesta a la encuesta de narradores. En: Abelardo Oquendo (selección.) Narrativa peruana 1950/1970. Madrid, Alianza Editorial, 1973, pp. 40-44.

Gutiérrez, Miguel (1988a). Hombres de caminos. Lima, Editorial Horizonte.

Gutiérrez, Miguel (1988b). La generación del 50: un mundo dividido. Lima, Sétimo Ensayo.

Gutiérrez, Miguel (1991). La violencia del tiempo. Lima, Editorial Milla Batres.

Gutiérrez, Miguel (1992). La destrucción del reino. Lima, Editorial Milla Batres.

Gutiérrez, Miguel (1993). Babel, el Paraíso. Lima, Colmillo Blanco.

Gutiérrez, Miguel (1995). Poderes secretos. Lima, Jaime Campodónico Editor.

Gutiérrez, Miguel (2002). El mundo sin Xóchitl. Lima, Fondo de Cultura Económica.

Gutiérrez, Miguel (2014). Kymper: Lima: Alfaguara. 